\title{
The New Four Planes of Symmetry in Crystallography
}

\author{
Suraj V Chavan ${ }^{1,}$ Sangram S Pawar $^{2}$, Sanjivani J Kshirsagar ${ }^{3}$ \\ Graduate Student, Mechanical Department, AGTI's Dr. Daulatrao Aher College of Engineering, Karad, India ${ }^{1,2}$ \\ Assistant Professor, Basic Science and Humanities, AGTI's Dr. Daulatrao Aher College of Engineering, Karad, India ${ }^{3}$
}

\begin{abstract}
The new four types of symmetry elements in a cubic crystal on the basis of planes passing through diagonal of crystal cube and mid-point of its two adjacent edges. The new four elements of symmetry have wide applications in 3D designing, vibrational study of molecules, classification of substances, etc.
\end{abstract}

Keywords: Crystal symmetry, plane, diagonal, edge mid-point, mirror image.

\section{INTRODUCTION}

The concept of symmetry is very powerful tool in and hexad axis. The diad axis is symbolise by 2 , triad axis theoretical physics; as this is manifest that practically all by 3 , tetrad axis by 4 , and the hexad axis by 6 , comparable laws of nature initiates in symmetries. The concept of to $180^{\circ}, 120^{\circ}, 90^{\circ}, 60^{\circ}$, rotations severally[3]. There is total symmetry elements in cubic crystal is first introduced by P 13 symmetry elements of axis of symmetry. As,

$\mathrm{W}$ ANDERSON in 1972. There is also Winger's classification, which says that the symmetries of the laws 2-fold axes (diad axes) :- 6 elements of symmetry of physics determine the properties of particles found in 3-fold axes (triad axes) :- 4 elements of symmetry nature.

In the section of planes of symmetry in symmetry elements of cubic crystal, we discovered new four planes of symmetry.

\section{CRYSTAL SYMMETRY:}

As a result of periodic arrangement there is some similarities of atomic arrangements that occur in crystals. This is called symmetry of atomic arrangement. The crystal is said to have a symmetry element corresponding to an operation, if after acting the specific activity the crystal goes into a position identical from the initial position. The most essential elements of symmetry are a center, an axis and a plane[1]. The three basic types of symmetry elements are described below:

\section{CENTER OF SYMMETRY:}

If a point exists inside the crystal such that the line drawn through it will have analogous condition at both of its ends, then the crystal is said to have a center of symmetry. This means that if there is an atom at some distance at one end, there is also an atom at the other end at the same distance[1]. It is also called the center of inversion. There is only one center of inversion, which is one of the symmetry elements[2].

\section{AXIS OF SYMMETRY:}

If the crystal is revolved about the axis, the atomic arrangement looks precisely the same more than once during one complete rotation. The diad axis is when the atomic arrangement looks the same two times in one rotation. Likewise, the axis may be a triad axis, tetrad axis,

4-fold axes (tetrad axes) :- 3 elements of symmetry

\section{PLANE OF SYMMETRY:}

If the crystal can be separated by an imaginary plane into two parts, such that one is the exact mirror image of the other, then the crystal is said to have a plane of symmetry. By the letter ' $\mathrm{m}$ ' the mirror plane is symbolised[2]. Commonly, the mirror plane is parallel to rotation axis or perpendicular to it.

i. Let us consider a plane such as PQRS (As shown in Figure 1.) in the middle of the cube and parallel to one pair of faces.

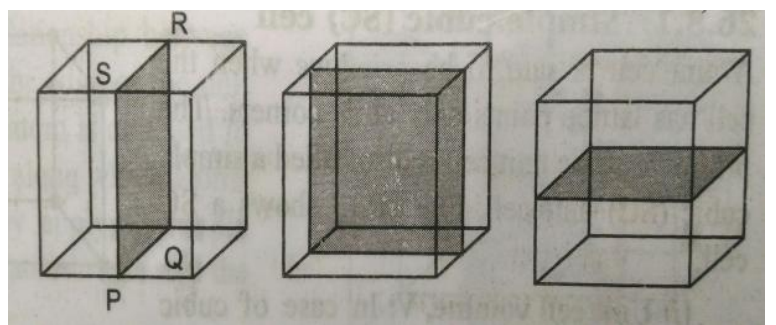

Fig.1. straight planes of symmetry

If it is considered as a mirror plane and one half of the crystal is cut and removed, the plane PQRS forms the mirror image of that half of the crystal in it. That means, the image will coincide with the other half, when we reflect one half of the crystal in plane PQRS. Thus, the plane PQRS is called a plane of symmetry or a mirror plane. There are three such planes of to parallel to the faces of the cube. 
IARJSET

ii. Now consider the diagonal plane KLMN (As shown in Figure 2.) in the cube.

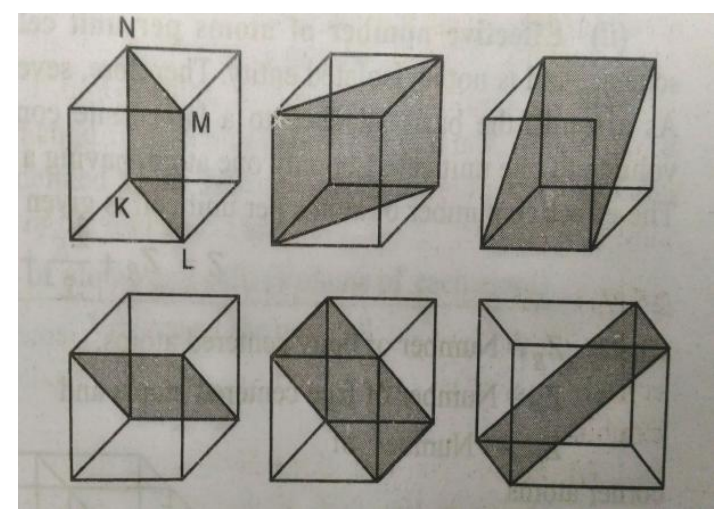

Fig.2.Diagonal planes of symmetry.

If KLMN is considered as a mirror, it is promptly seen that the prism backside it is the reflection of the prism in touch with it in its front. Therefore it is also a mirror plane. There are such six types of diagonal mirror planes in a cube.

iii. We have newly discovered the four planes of symmetry.

Now consider the plane of symmetry passing through diagonal of crystal cube and mid-point of its two adjacent edges as ABCD (As shown in Figure 3.) in the cube.

\section{THE NEW 4 PLANES OF SYMMETRY:}

Previously there are total 9 planes of symmetries, as straight planes of symmetry 3 in number and diagonal planes of symmetry 6 in number. But we discovered new 4 planes of symmetry which are passing through diagonal of a cube and mid-point of its two adjacent edges. These planes of symmetry are explained in detail as below: First consider a cube having all edges equal in length. Then consider imaginary plane $\mathrm{ABCD}$ as shown in figure 3, which exactly passing through diagonal of cube and midpoint of its two adjacent edges.

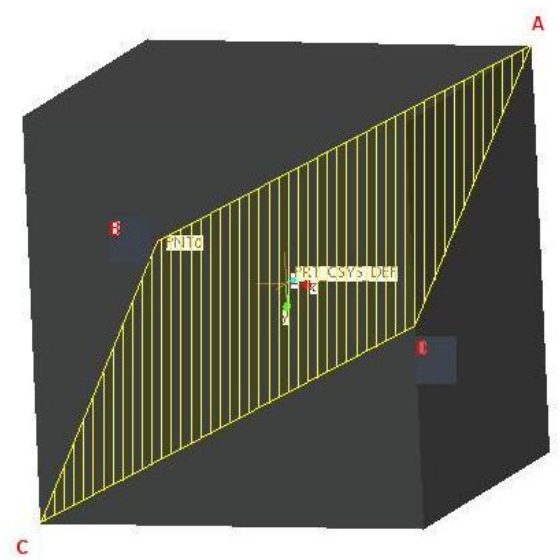

Fig.3.1.First plane.
This imaginary plane divides the crystal cube into two equal parts, in which one is exact mirror image of the other. As a condition of plane of symmetry, the mirror plane ABCD is parallel to rotation axis or perpendicular to it. If we pass plane starting from one corner point of upper face of a cube and ends at opposite corner point of lower face. This results into one plane of symmetry.

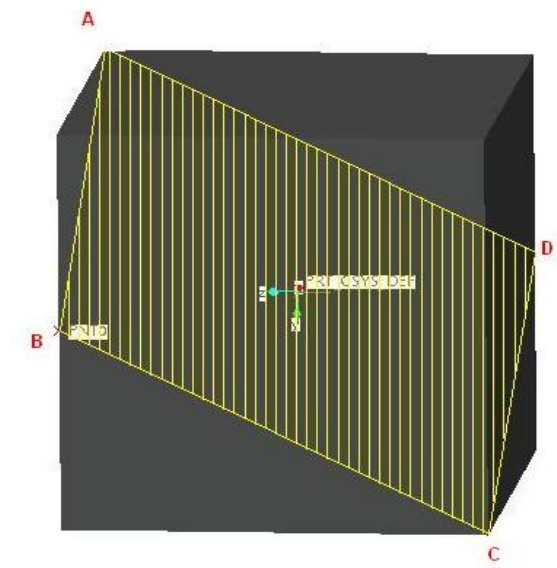

Fig.3.2.Second plane

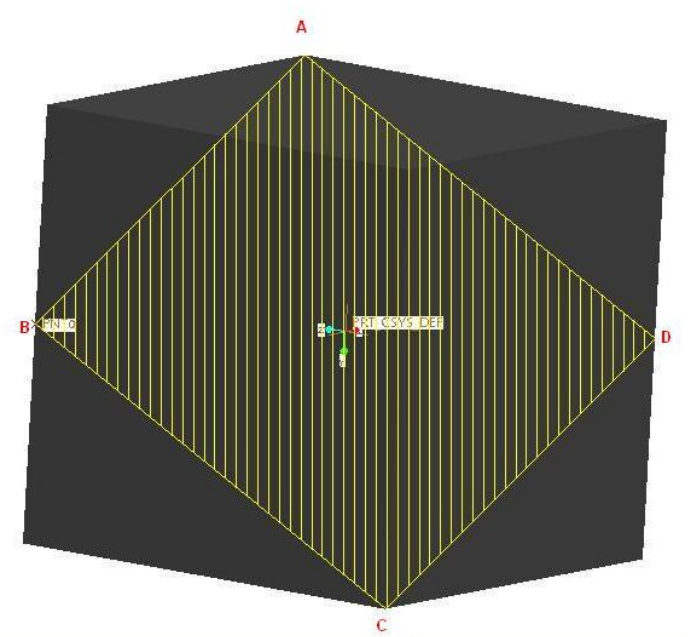

Fig.3.3.Third plane.

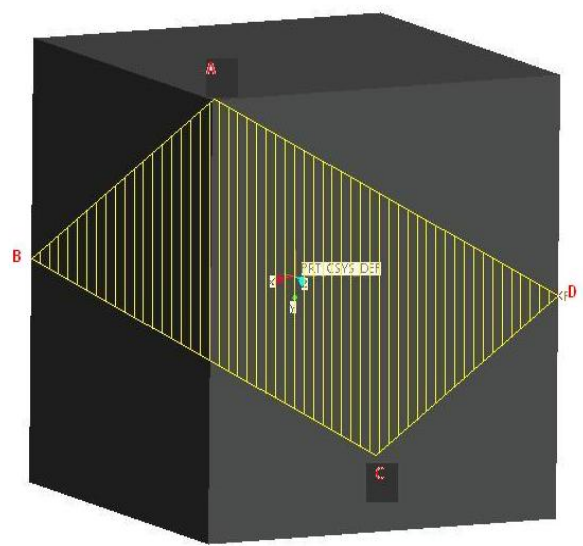

Fig.3.4.Fourth plane 
IARJSET

Thus for a one cube there are total 8 corner points and through these points total 4 diagonals are passing. From these 4 diagonals total 4 planes are passing which cuts the cube into two equal parts. These 4 planes are also passing through mid-point of cube's two adjacent edges. This results into total 4 planes of symmetry on the basis of planes passing through diagonal of crystal cube and midpoint of its two adjacent edges. These 4 planes of symmetry are shown in Fig. 3.1, Fig. 3.2, Fig. 3.3, and Fig. 3.4. These four planes of symmetry are exactly similar to each other in dimensions. The two equal parts created by this plane are exactly mirror image of each other.

\section{EXPERIMENTAL ANALYSIS}

1. From PRO-E Software we observed that, if we cut cube into two equal parts by passing a plane through diagonal of crystal cube and mid-point of its two adjacent edges then that two parts are same in mass and volume.

We observed in the observation table 3 and 4 that the mass of total cube equal to 7.8000000e+09 TONNE and volume is $1.0000000 \mathrm{e}+06 \mathrm{MM}^{3}$ (As shown in Figure 4.1 and 4.2). After cutting the cube by plane ABCD then one part $(\mathrm{M}$ or $\mathrm{N})$ has mass and volume is $3.9000000 \mathrm{e}+09$ TONNE and 5.0000000e+05 $\mathrm{MM}^{3}$ respectively (As shown in figure 4.3 and 4.4). Consider $\mathrm{M}$ and $\mathrm{N}$ is two parts of cube after cutting along the imaginary plane ABCD, then mirror image of part $\mathrm{M}$ is similar to part $\mathrm{N}$ as shown in Fig. 4.1 and Fig.4.2

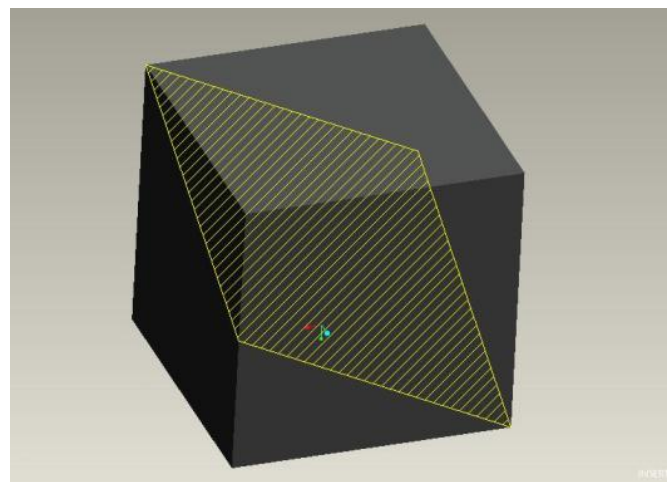

Fig.4.1. Whole cube

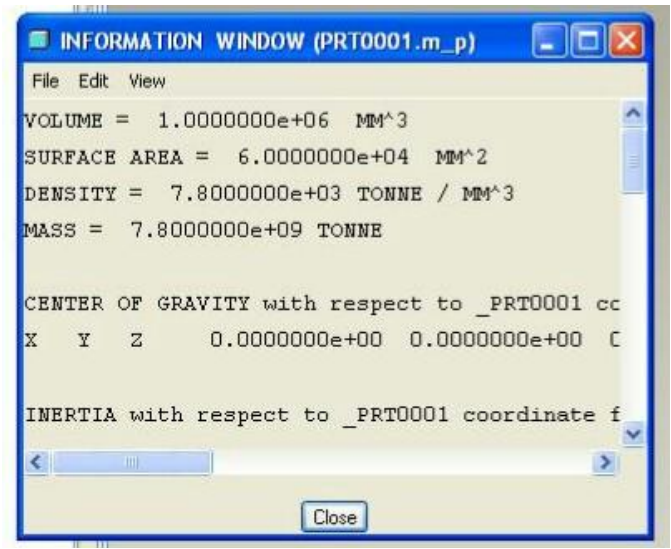

Fig.4.2.Volume, Density and Mass of whole cube

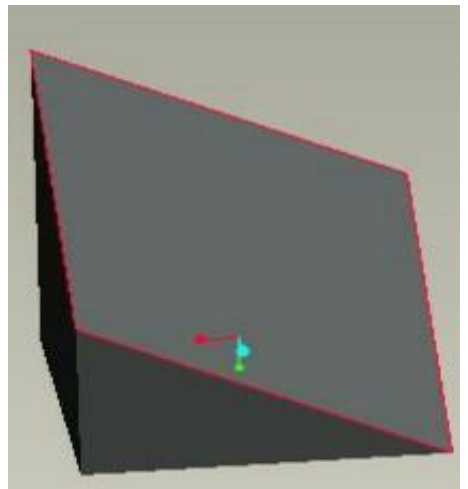

Fig.4.3.One piece of cube ( $\mathrm{M}$ or $\mathrm{N}$ ) after cutting by plane $\mathrm{ABCD}$.

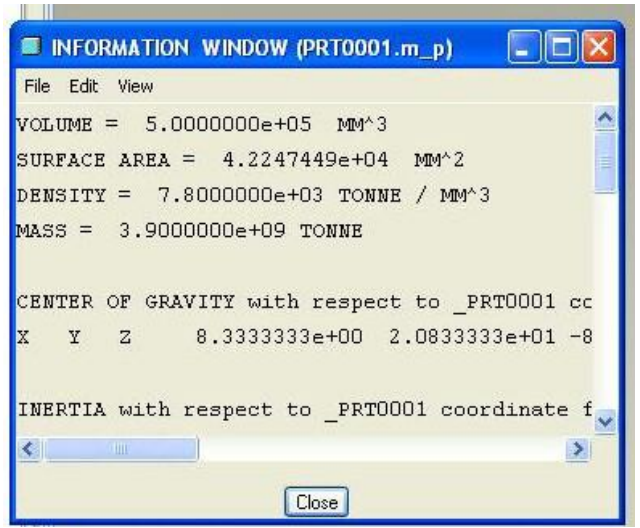

Fig.4.4.Volume, Density and Mass of one piece of cube (M or $\mathrm{N}$ ) after cutting by plane ABCD.

From this study it is proved that when we cut the cube by plane passing through diagonal and mid-point of its two adjacent edges then these two parts of cube are equal and one part is mirror image of other.

2. For the experimental validity of this concept we took a wooden cube and cut it into two parts along the plane ABCD. Let us consider the one part of cube is $\mathrm{P}$ and other is $\mathrm{Q}$.

We observed in observation tableland 2 the mass of wooden cube is equal to 162 GRAM and volume is $300763 \mathrm{MM}^{3 .}$ After cutting the cube along the plane $\mathrm{ABCD}$, then we observed one part ( $\mathrm{P}$ or $\mathrm{Q}$ ) has mass equal to $81 \mathrm{GRAM}$ and volume is equal to $150381.5 \mathrm{MM}^{3}$.

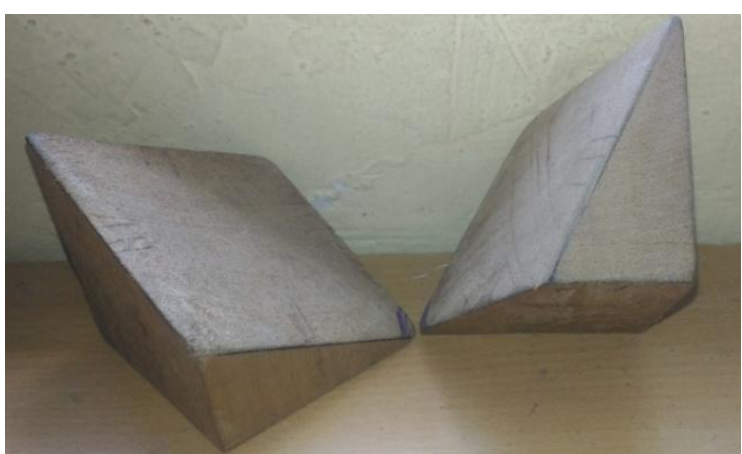

Fig.5.A wooden block after cutting into two pieces $\mathrm{M}$ or $\mathrm{N}$ 
IARJSET

International Advanced Research Journal in Science, Engineering and Technology

National Conference on Design, Manufacturing, Energy \& Thermal Engineering (NCDMETE-2017)

AGTI's Dr. Daulatrao Aher College Engineering, Vidyanagar Extension, Karad

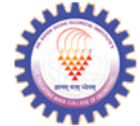

Vol. 4, Special Issue 1, January 2017

Consider $\mathrm{P}$ and $\mathrm{Q}$ is two parts of cube after cutting along The crystal elements have wide applications in symmetry the plane $\mathrm{ABCD}$, then mirror image of $\mathrm{P}$ is similar to part classification of molecules of substances. The symmetry $\mathrm{Q}$ as shown in Fig. 5.

From this experiment it is proved that that when we cut the cube by plane passing through diagonal and mid-point of its two adjacent edges then these two parts of cube are equal and one part is mirror image of other.

\section{OBSERVATION TABLES}

\section{Tables of experimental study}

Table 1: Table of mass:

\begin{tabular}{|l|l|l|l|}
\hline $\begin{array}{l}\text { Sr. } \\
\text { No. }\end{array}$ & $\begin{array}{l}\text { Weight of } \\
\text { whole cube } \\
\text { in gram }\end{array}$ & $\begin{array}{l}\text { Weight of part } \\
\text { P in gram }\end{array}$ & $\begin{array}{l}\text { Weight of } \\
\text { part Q in } \\
\text { gram }\end{array}$ \\
\hline 1. & 162 & 81 & 81 \\
\hline
\end{tabular}

Table 2: Table of volume:

\begin{tabular}{|l|ll|l|l|}
\hline $\begin{array}{l}\text { Sr. } \\
\text { No. }\end{array}$ & $\begin{array}{l}\text { Volume of } \\
\text { whole cube in } \\
\mathrm{mm}^{3}\end{array}$ & $\begin{array}{l}\text { Volume of } \\
\text { part P in } \\
\mathrm{mm}^{3}\end{array}$ & $\begin{array}{l}\text { Volume of } \\
\text { part Q in } \\
\mathrm{mm}^{3}\end{array}$ \\
\hline 1 & 300673 & 150381.5 & 150381.5 \\
\hline
\end{tabular}

Tables of PRO-E software study:

Table 3: Table of weight:

\begin{tabular}{|l|l|l|l|}
\hline $\begin{array}{l}\text { Sr. } \\
\text { No }\end{array}$ & $\begin{array}{l}\text { Weight of } \\
\text { whole cube in } \\
\text { tonne }\end{array}$ & $\begin{array}{l}\text { Weight of part } \\
\mathrm{M} \text { in tonne }\end{array}$ & $\begin{array}{l}\text { Weight of } \\
\text { part N in } \\
\text { tonne }\end{array}$ \\
\hline 1. & $\begin{array}{l}7.8000000 \\
\text { e+09 }\end{array}$ & $\begin{array}{l}3.9000000 \\
\text { e+09 }\end{array}$ & $\begin{array}{l}3.9000000 \\
\text { e+09 }\end{array}$ \\
\hline
\end{tabular}

Table 4: Table of volume:

\begin{tabular}{|l|l|l|l|}
\hline $\begin{array}{l}\text { Sr. } \\
\text { No }\end{array}$ & $\begin{array}{l}\text { Volume of the } \\
\text { whole cube in } \\
\mathrm{mm}^{3}\end{array}$ & $\begin{array}{l}\text { Volume of } \\
\text { part M in } \\
\mathrm{mm}^{3}\end{array}$ & $\begin{array}{l}\text { Volume of } \\
\text { part N in } \\
\mathrm{mm}^{3}\end{array}$ \\
\hline 1. & $\begin{array}{l}1.0000000 \\
\mathrm{e}+06\end{array}$ & $\begin{array}{l}5.0000000 \\
\mathrm{e}+05\end{array}$ & $\begin{array}{l}5.0000000 \\
\mathrm{e}+05\end{array}$ \\
\hline
\end{tabular}

\section{RESULTS AND DISCUSSIONS}

This research is related with symmetry elements of crystal structure. Previously there are total 23 symmetry elements of cubic crystal. In that there is total 9 planes of symmetry. But now we found newly 4 planes of symmetry, which are based on plane passing through diagonal of crystal cube and mid-point of its two adjacent edges. By adding these 4 planes of symmetry, there will be 13 planes of symmetry. Thus total 23 symmetry elements in cubic crystal modified to total 27 symmetry elements of cubic crystal [6].

Symmetry is one of the most omnipotent concepts in science and can be used to describe animate and inanimate objects of nature and man-made products. elements are very useful to determine the number of vibrational modes in a molecule. Due to new 4 planes of symmetry there will be new modes of molecular vibration, which are very useful in vibration analysis[7]. Due to these new 4 types of planes of symmetry there is development of wide applications in the sector of $3 \mathrm{D}$ scanners and 3D printing devices as well as in 3D designing in future. The symmetry elements also can be used for categorizing and organizing the 3D geometry of shapes.

\section{CONCLUSION}

Hence we discovered successfully the new 4 planes of symmetry elements in a cubic crystal on the basis of a plane passing through diagonal of a crystal cube and midpoint of its adjacent edges.

This discovery of new 4 planes of symmetry helps in study of molecular vibrations of physical substances, which leads to new creative research in molecular vibrations. This research gives the revolution in the sector of physical sciences.

\section{REFERENCES}

[1] A Textbook Of Engineering Physics by "Dr. M. N. Avadhanulu, Dr. P. G. Kshirsagar" ] S. CHAND Publications, pp. 761-763, 2014. ISBN-10, 8121908175

[2] A Textbook Of Engineering physics by "Dr. M. N. Avadhanulu, Dr. P. G. Kshirsagar" S. CHAND Publications, , pp. 475-477, 2011. ISBN-10, 8121908175

[3] Mahalaxmi Publications, Engineering Physics, by "C. S. Kali, D. N. Balte, B. N. Shinde, "Dr. P. M. Kulal, D. N. Palekar", Mahalaxmi Publications pp. 4-32-4-35.

[4] Biserka Kojic-Prodic, Zoran Stefanic", Research Paper; Symmetry Versus Asymmetry In The Molecule Of Life: Homomeric Protein Assemblies, ISSN 2073-8994.

[5] "Dobre, D"., (2008), Development Basics of a Product (Bazeledezvoltarii de produs), Bucharest, Romania.

[6] "Dobre D., Simion I"., (2009), Special applications off air surfaces representation, The 3rd International Conference on Engineering Graphics and Design, in Acta Technica Napocensis, Series: Applied Mathematics and Mechanics, no. 52, vol. Ia, pp. 273-278, ClujNapoca, Romania.

[7] Niloy J. Mitra, Mark Pauly, Michael Wand, Duygu Ceylan, Symmetry In 3D Geometry: Extraction And Applications Pdf.,'http://vecg.cs.ucl.ac.uk/Projects/SmartGeometry/symmetry_s urvey/paper_docs/symmetryStar_small_EG12.pdf

[8] Claire Vallance, Molecular Symmetry, Group Theory And Applications, Pdf," http://vallance.chem.ox.ac.uk/pdfs/Symmetry LectureNotes2006.pdf 